\title{
Entre 0 rádio e a televisão: gênese e transformações das novelas brasileiras ${ }^{1}$
}

\section{Eduardo Vicente e Rosana de Lima Soares}

\section{Resumo}

Este artigo oferece um olhar sobre a radionovela no Brasil e as relações que se estabeleceram entre esse gênero e 0 das telenovelas. Inicialmente, apresentaremos aquelas que consideramos as duas tendências principais da ficção radiofônica no país: uma mais comercial, ligada ao melodrama e de caráter conservador, outra realista e politicamente engajada. Depois, discutiremos como essa segunda tendência, embora menos presente no rádio, foi de grande importância no desenvolvimento da telenovela. Finalmente, proporemos que a telenovela tornou-se a principal referência para a atualização da linguagem das radionovelas no projeto de produção desenvolvido pela SSC\&B Lintas durante os anos 1980.

\section{Palavras-Chave}

História da mídia. Ficção radiofônica. Radionovela. Telenovela.

Eduardo Vicente I eduvicente@usp.br Doutor em Ciências da Comunicação pela Universidade de São Paulo, Brasil. Professor Associado do Programa de Pós-Graduação em Meios e Processos Audiovisuais da Universidade de São Paulo.

Rosana de Lima Soares | rolima@usp.br Doutora em Ciências da Comunicação pela Universidade deSão Paulo, Brasil. Professora Associada do Programa de Pós-Graduação em Meios e Processos Audiovisuais da Uhiversidade de São Paulo.

\section{Introdução}

Este texto busca apresentar um pouco da história e algumas das principais características das radionovelas brasileiras, cuja produção teve seu auge entre as décadas de 1940 e 1950. Sua intenção é apontar, entre outros aspectos, para as relações que se estabeleceram entre elas e as telenovelas, que começaram a ser produzidas no país durante os anos 1960.

Inicialmente, apresentaremos um breve relato acerca do início da produção de radionovelas no Brasil exemplificando o desenvolvimento desta tradição a partir da atuação de José Castellar (1923-1994), cujos trabalhos trazem muitas das principais características da radionovela no Brasil: a influência do rádio cubano, histórias ambientadas em locais exóticos ou no passado e a ausência de conflitos sociais²

A seguir, apresentaremos uma segunda vertente do rádio ficcional brasileiro representada, entre outros autores, por Dias Gomes (1922-1999). Em seus trabalhos teremos a predominância 
da temática realista, da crítica social, do

engajamento político, de elementos da cultura

popular e de produções ambientadas no

Brasil, com personagens mais próximos à

realidade econômica e social dos ouvintes.

Essa vertente, como veremos, aproxima-se

bastante das características que se tornariam

definidoras de nossas telenovelas que, em seus

momentos iniciais, estiveram mais próximas das

radionovelas tradicionais.

Finalmente, discutiremos a produção

de radionovelas no Brasil dos anos 1980

apresentando a produção radiofônica da SSC\&B-

Lintas, a housing agency das Indústrias Gessy

Lever. Ao longo daquela década, milhares de

horas de programas ficcionais (radionovelas,

séries e adaptações) foram produzidas por essa

empresa de São Paulo e veiculadas por centenas

de rádios do interior do país, especialmente

nas regiões Norte e Nordeste. Um dos pontos a

ser defendido neste artigo é o de que o projeto

da SSC\&B-Lintas representou um importante

momento de atualização da linguagem

da radionovela no Brasil e foi fortemente

influenciado pela telenovela.

\section{0 início da radionovela no Brasil}

Podemos vincular o início da radionovela no Brasil a iniciativas praticamente simultâneas da filial brasileira da empresa norte-americana ColgatePalmolive, e do autor e diretor de cinema e teatro Oduvaldo Vianna (1892-1972).

0 interesse da Colgate-Palmolive pelas radionovelas está ligado à chegada ao Brasil, no início dos anos 1940, do norte-americano Richard Penn, nomeado gerente-geral da empresa no país. Mr. Penn, como se tornaria conhecido, chega transferido da filial cubana da Colgate e, segundo José Castellar, que trabalhou com ele por vários anos, "veio entusiasmado com a radionovela e lançou Em Busca da Felicidade"3. Essa radionovela "foi ao ar em 5 de junho de 1941, pela Rádio Nacional do Rio de Janeiro. A radionovela era uma adaptação de Gilberto Martins do original cubano de Leandro Blanco" (BORELLI; MIRA, 1996, p. 34). Em Busca da Felicidade tornou-se a primeira radionovela produzida e veiculada no país, e a Colgate-Palmolive, um dos maiores patrocinadores do rádio brasileiro, promovendo especialmente radionovelas.

0 presente texto é a versão revista e atualizada da comunicação "Radio vs. Television in Brazil: the in-between media genesis and development of Brazilian so ap operas", apresentada na ECREA Radio Research Section Conference, realizada em outubro de 2015 em Madri (Espanha), e selecionada pelos organizadores para publicação, em inglês em Radio, Sound \& Society Journal (v.1, n.1, 2016).

A discussão da obra de José Castellar foi feita a partir da análise de roteiros que integram o Acervo Castellar, organizado e disponibilizado por Eduardo Vicente (ECA/USP) e Rafael Duarte Oliveira Venâncio (UFU) nas dependências da Escola de Comunicações e Artes da USP.0 acervo, que pertencera anteriormente ao Núcleo de Telenovelas da instituição, conta com roteiros de programas de rádio e televisão escritos por José Castellar, Heloisa Castellar (1921-1995) e Thalma de Oliveira (1917-1976). 
Já para Oduvaldo Vianna, o primeiro contato com a radionovela aconteceu em Buenos Aires, para onde ele se mudou em 1939 por razões profissionais. Lá, foi "convidado pelo Instituto Brasileiro do Café para fazer um programa na Radio El Mundo, de propaganda de nosso café, com músicas brasileiras e um radiodrama de dez minutos sobre o nosso folclore" (VIANNA, 1984, p. 66). No ano seguinte, segundo depoimento do próprio Oduvaldo,

Carmen Valdez, da Radio El Mundo, me procurou para que eu escrevesse uma novela para 0 elenco daquela emissora, que ela estrelava. Confessei-Ihe que não conhecia 0 gênero. Ela levou-me ao estúdio de rádio-teatro. Depois de assistir do controle a um capítulo que ia ao ar, fiquei afinal sabendo o que era uma novela radiofônica. E lá, na Radio El Mundo, comecei. (...) A minha popularidade daí por diante era a novela... No setor feminino então chegava a me irritar. Ninguém se lembrava de nada que eu havia feito, a não ser las novelas. Senti, confesso. Mas eu vivia exclusivamente de escrever e o remédio foi continuar (VIANNA, 1984, p. 68).

Oduvaldo volta ao Brasil em 1940 e, no ano seguinte, torna-se diretor da Rádio São Paulo, onde lança $A$

Predestinada, radionovela de sua autoria. Trata-se da primeira radionovela de autor nacional veiculada no país, tendo ido ao ar alguns meses depois de Em Busca da Felicidade (ORTIZ, 1991, p. 25).

0 sucesso é imediato e provoca grandes mudanças no rádio brasileiro. A Rádio São Paulo, por exemplo, passa a ocupar os principais horários de sua programação com radionovelas. Já a Rádio Nacional do Rio de Janeiro foi responsável pelas produções de maior repercussão, várias delas patrocinadas pela Colgate-Palmolive. Esse foi o caso, por exemplo, de O Direito de Nascer, certamente a radionovela de maior sucesso da história do rádio brasileiro. Adaptada do original do escritor cubano Felix Caignet, estreou em janeiro de 1951, teve 314 capítulos e permaneceu no ar por quase três anos (CALABRE, 2007, p. 83) ${ }^{4}$. Posteriormente, Oduvaldo Vianna iria se transformar no mais importante autor de radionovelas da Nacional, para a qual escreveu 75 produções do gênero (CALABRE, 2007, p. 74).

A obra de José Castellar (1923-1994), um dos mais importantes autores de radionovelas do rádio de São Paulo, permite-nos conhecer algumas das características que essa produção assumiu no país. Castellar, que escreveu dezenas de radionovelas durante a Era de Ouro do rádio brasileiro, começou sua carreira por volta de 1944, no Rio de Janeiro, como redator da Standard Propaganda. A agência, criada em 1933 por Cícero Leuenroth, era responsável pela conta da Colgate-Palmolive. 0 primeiro trabalho de Castellar dentro da empresa foi justamente 0 de escrever uma radionovela.

Ainda nos anos 1940, ele foi transferido para São Paulo, onde se fixou, "entre outras coisas, 
para adaptar as radionovelas de Leandro

Blanco" para a Colgate-Palmolive ${ }^{5}$. Dentre as

102 obras radiofônicas do autor que fazem parte

do acervo, há uma forte predominância dos

trabalhos ficcionais, especialmente radionovelas

e peças radiofônicas. Gostaríamos de apresentar

brevemente alguns de seus trabalhos.

Muitas de suas obras são adaptações de livros estrangeiros. Castelo Encantado (Radio Difusora, 1945), por exemplo, foi baseada no romance $O$

Solar de Dragonwyck, de Anya Seton. Já O Sheik (Rádio São Paulo, 1950) foi baseada na obra homônima de E. M. Hull. A Flecha da Vingança (Rádio São Paulo, 1950) foi livremente baseada no livro A Flecha Negra, de Robert Louis Stevenson, ambientada na Inglaterra do final do século XV. Entre os textos originais, destacamos $O$ Coração Que Eu Roubei (Rádio Tamoio, 1951), que traz a história de Ernesto, jovem da alta sociedade paulistana no período da monarquia brasileira. Ao longo da obra, o protagonista relata na prisão, a seus dois companheiros de cela, as desventuras por que passou e sua condenação por um crime que não cometeu em nome de seu amor por uma mulher. Ao final da trama, 0 protagonista alcança a sua liberdade, recupera sua fortuna e casa-se com a amada.

Temos, em todos os casos, produções ambientadas em períodos históricos ou locais distantes da realidade dos ouvintes e com tramas que não evocam problemas ou questões de sua atualidade. Temos também, nessas e em outras obras de Castellar, um recurso constante ao mistério, ao suspense, à aventura, ao romance, à exacerbação dos sentimentos, ao conflito entre 0 bem e o mal, e a outros elementos tradicionais do melodrama, em produções claramente dirigidas ao público feminino.

Ao analisar os roteiros de 34 radionovelas da Rádio Nacional, do Rio de Janeiro, veiculadas entre os anos de 1944 e 1946, Lia Calabre apresenta algumas das características básicas das produções daquela emissora. Inicialmente, Calabre classifica os roteiros em seis categorias, dividindo-os entre romance, mistério, aventura, comédia, suspense e drama, sendo estes últimos os mais frequentes (13 de 34 roteiros). Dramas e histórias de suspense também se destacam dentro da produção de Castellar. Porém, em relação à ambientação das produções, há uma diferença importante: Calabre identifica a predominância de radionovelas ambientadas no meio urbano, especialmente na cidade do Rio e no tempo presente.

No entanto, ela destaca que as radionovelas traziam como protagonistas, quase que invariavelmente, representantes das classes abastadas: "um mundo constituído por profissionais liberais e empresários, ou seja, um mundo composto pelas classes média e alta" 
(CALABRE, 2006, p. 189). Assim, "as mazelas da cidade quase não aparecem nas radionovelas. (...) A cidade destes personagens era a das mansões, das casas confortáveis, dos bairros urbanizados, com carros e motoristas particulares" (CALABRE, 2006, p. 189).

Como características das radionovelas, José Castellar destacava ainda a interpretação afetada e pouco natural dos atores, o uso predominante da norma culta da língua e 0 recurso constante ao "narrador onisciente", que descrevia personagens, cenários e fatos desconhecidos dos protagonistas da trama ${ }^{6}$.

A partir dos exemplos apresentados, entendemos que é possível afirmar a predominância de uma visão conservadora da sociedade e de seus valores nas radionovelas produzidas durante os anos 1940 e 1950. Miriam Goldefeder, em seu estudo sobre a Rádio Nacional, ressalta o papel da sua programação, inclusive das radionovelas, enquanto "mecanismo de controle social" e "espaço de convergência dos valores morais conservadores típicos dos setores médios" (GOLDEFEDER, 1980, p. 84).

Entretanto, embora essa visão conservadora da sociedade e o protagonismo das classes abastadas tenham sido tendências dominantes dentro da produção de radionovelas, é possível apontar para a existência de produções do período, principalmente séries radiofônicas, as quais expressavam outras visões em termos políticos e ideológicos. Menos influente no rádio, essa tendência vinculava-se, em razoável medida, à atuação de artistas ligados ao pensamento político de esquerda, especialmente a intelectuais do Partido Comunista Brasileiro (PCB), fundado em 1922. Iremos, a seguir, dedicar-nos à discussão dessa outra tendência da ficção radiofônica no Brasil, politicamente engajada e voltada para temáticas contemporâneas, de caráter mais realista.

\section{A politização do rádio ficcional no Brasil}

Ao identificar características da produção de intelectuais ligados ao PCB, Marcos Napolitano destaca, entre outras,

a opção pelo nacionalismo, a visão de povo como protoconsciência revolucionária, o papel mediador do artista-intelectual e o realismo como princípio da comunicação com o público (implicando no figurativismo nas artes, na defesa da canção como convenção melódica suportando uma mensagem poética e o realismo dramatúrgico no cinema e no teatro) (NAPOLITANO, 2012, p. 101).

Entendemos que poderíamos incluir também 0 rádio nesta lista. Isso pode ser exemplificado através da obra de Alfredo de Freitas Dias Gomes (1922-1999), que atuou no meio entre os anos de 1944 e 1964. Dias Gomes filiou-se ao PCB em 1945 e teve a sua produção artística fortemente marcada 
por seu engajamento político, fato que determinou a sua demissão de várias das emissoras pelas quais passou (DIAS GOMES, 1998).

Em trabalho anterior, analisamos uma das produções radiofônicas desse autor (VICENTE, 2013). Trata-se de A História de Zé Caolho, uma peça radiofônica de 22 minutos de duração veiculada em 1952 pela Rádio Bandeirantes, de São Paulo, dentro da série radiofônica "Sonho e Fantasia". A História de Zé Caolho é uma das raríssimas gravações de uma obra ficcional radiofônica dos anos 1950 ainda existente no Brasil.

Em Zé Caolho, Dias Gomes apresenta a história de um lavrador cearense, Zé Zeferino, que chega à cidade de São Paulo na esperança de conseguir emprego e uma vida melhor. Ao fracassar nesse objetivo, Zé Zeferino torna-se Zé Caolho, um mendigo que finge ser cego de nascença. Após receber um pacote contendo uma grande soma em dinheiro de uma bela e misteriosa mulher, 0 protagonista torna-se um homem rico e concorre à Presidência da República, prometendo o fim da pobreza no país. Ao final, descobrimos que tudo não passava de um sonho do protagonista.

Assim, temos não apenas uma produção ambientada na contemporaneidade paulistana do período, como também protagonizada por mendigos e não pelos "profissionais liberais e empresários" citados por Calabre. A produção, além do forte tom de crítica social, apresenta interessantes inovações estéticas, como o uso da canção popular - inclusive de forma não diegética - enquanto forma de comentário épico da ação, a atribuição de vozes a objetos inanimados (em uma clara influência de Brecht), interpretações naturalistas e um uso bastante econômico do narrador onisciente (VICENTE, 2013). Além de Dias Gomes, podem ser citados outros autores de rádio que realizaram, nos anos 1950, obras de caráter mais realista e de maior engajamento político.

Talvez o principal exemplo seja 0 da série radiofônica Histórias das Malocas, de Osvaldo Molles (1913-1967). Molles produziu uma vasta obra radiofônica, além de ter escrito trabalhos para teatro e cinema. Histórias das Malocas é o mais importante de seus trabalhos. Produzida para a Rádio Record, de São Paulo, a série foi veiculada entre 1954 e 1966. Seus protagonistas eram os moradores das malocas e os diálogos da série reproduziam as incorreções gramaticais e as expressões características dos habitantes pobres da periferia de São Paulo.

Embora fosse uma série cômica, Histórias das Malocas acabava por levar a um público de classe média alguns dos problemas dessa parcela "invisível" da população, como a fome, o desemprego, a perseguição policial e mesmo a discriminação racial. Um dos personagens da série, o negro Zé Conversa, por exemplo, reclama em um dos episódios dos brancos que não querem que ele caminhe pela Rua Direita, uma importante rua comercial no centro de São Paulo: "A rua é livre! Eu sou preto, sou brasileiro e passeio na Rua 
Direita quando quiser. E ninguém vai bater em mim!" (MUGNAINI JR., 2002, p. 54).

Outro exemplo que merece menção é o da Ópera em 1040 Quilociclos, criada por Túlio de Lemos, também em 1952, para a Rádio Tupi de São Paulo. Esta série radiofônica trazia temas de óperas célebres adaptados criticamente ao contexto social e político da São Paulo dos anos 1950. Irineu Guerrini Jr. (2013), que realizou um importante estudo sobre a obra de Túlio de Lemos, afirma que, na adaptação de Lo Schiavo, de Carlos Gomes, por exemplo, a trama é transplantada do Rio de Janeiro, de 1801, para uma fazenda de São Paulo, em 1952. Em lugar da paixão entre a índia escrava e o filho do Conde, dono da fazenda, temos a paixão entre a trabalhadora rural e o filho do proprietário. Na história original, a heroína é obrigada pelo Conde a se casar com outro índio, que depois se suicida, deixando o caminho aberto para 0 amor entre ela e 0 filho do Conde.

Já na versão de Túlio, a heroína, casada com um empregado da fazenda, não volta para 0 filho do patrão: "Renegando o seu passado relativamente privilegiado de criada da casa dos donos da fazenda, prefere partir com seu marido em busca de uma vida independente e rejeitar o jovem apaixonado" (GUERRINI JR., 2013, p. 134).

Assim, parece-nos possível afirmar que, ao longo dos anos 1950, tivemos o surgimento no país de obras ficcionais de rádio que, fugindo da tradição das radionovelas, enveredavam pela crítica social e política. Nesse sentido, o rádio se aproximava de movimentos que se desenvolviam em outras áreas de produção cultural brasileira como o cinema (Cinema Novo), a música popular (Tropicalismo, Canção de Protesto), a literatura e 0 teatro (Teatro de Arena e Teatro Oficina).

Não se tratava, de qualquer modo, de uma tendência de grande destaque no rádio. De maneira geral, ela esteve restrita a alguns poucos autores radiofônicos, principalmente de São Paulo, que mantiveram alguma ligação com o PCB (caso de todos os nomes aqui citados). Deve-se acrescentar ainda que 0 Golpe Militar de 1964 determina o fim dessas iniciativas, bem como da carreira radiofônica de Dias Gomes, que acaba sendo demitido da Rádio Nacional (Dias Gomes, 1999). Além disso, o avanço da televisão irá determinar o rápido declínio da produção ficcional radiofônica ao longo dos anos 1960.

Mas, ainda que essa opção pelo realismo, pelas questões nacionais e pela crítica social esteja vinculada a uma produção marginalizada dentro de um rádio fortemente influenciado pela atuação das agências de publicidade e pela presença hegemônica do melodrama tradicional, entendemos que ela apresenta uma interessante ligação com 0 desenvolvimento da telenovela no Brasil. É a essa questão que nos dedicaremos a seguir.

\section{A telenovela no Brasil}

Embora não tenhamos a pretensão de oferecer um relato mais detalhado sobre 0 início da 
telenovela no Brasil, gostaríamos de destacar que muitas das características presentes nas radionovelas brasileiras tradicionais também estiveram presentes nas telenovelas em sua fase inicial. Mariane Murakami, ao falar das primeiras produções do gênero, as quais começam a ser veiculadas no país a partir de 1951, lembra que nelas se destacaram "os roteiros nos moldes dos desenvolvidos pela cubana Gloria Magadan - dramalhões com fórmulas infalíveis que retomavam as características do melodrama" (MURAKAMI, 2015, p. 38). Armand e Michèle Mattelart, referindo-se a esse mesmo período, descrevem uma profusão de "masmorras, calabouços, tavernas, hospitais e saídas secretas de castelos mal-assombrados, com personagens estereotipados" (MATTELART; MATTELART, 1990$, p. 15$)^{7}$.

\section{Gloria Magadan (María Magdalena Iturrioz y}

Placencia) trabalhou na Rede Globo entre 1965 e 1969 e foi, sem dúvida, uma figura central nesse momento inicial da telenovela no Brasil. Nascida em Havana (Cuba) nos anos 1920, escreveu sua primeira radionovela, Cuando Se Quiere un Enemigo, em meados dos anos 1940. Pouco depois, foi contratada pelo departamento de publicidade da Colgate-Palmolive, empresa pela qual iria atuar até 1965. Exilada de Cuba desde 1961, Magadan se mudou para o Brasil em 1964 e começou a trabalhar na Rede Globo no ano seguinte. Segundo o site Memória Globo, ela acumulou

(...) as funções de escritora, produtora e supervisora de novelas, nas quais procurou adaptar a linguagem folhetinesca para 0 Brasil, ainda que suas obras não retratassem diretamente a realidade do país. Conhecida à época como "rainha da telenovela", imprimia um estilo meIodramático, privilegiando tramas de capa e espada, romanticamente fantasiosas e, em geral, ambientadas em longínquos cenários. (...)

No entanto, ao final dos anos 1960,

(...) começou a surgir na televisão brasileira uma demanda por narrativas que mostrassem histórias nacionais, com traços mais realísti$\cos ^{8}($....). Entrava em cena 0 cotidiano da vida urbana e da modernização brasileira, tendo por maior representante Beto Rockfeller (1968), novela de autoria de Bráulio Pedroso exibida pela Tupi. Na Globo, o estilo de Janete Clair e Dias Gomes passa a ser cada vez mais valorizado.

Nesse processo, Magadan deixa a emissora em 1969 e Janete Clair passa a ocupar a posição de mais importante autora de telenovelas com diversas obras, entre elas Vestido de Noiva (1969), Irmãos Coragem (1970), Selva de Pedra (1972) e Pecado Capital (1975) e O Astro (1977). Dias Gomes, marido de Janete Clair, também se tornaria um autor de destaque da emissora por meio de produções como Bandeira 2 (1971), O Bem Amado (1973), Saramandaia 
(1976), Roque Santeiro (1985) e Mandala

(1988). Nos trabalhos de ambos, o uso da canção

popular, a presença de representantes das classes trabalhadoras, as histórias ambientadas nas periferias urbanas ou no interior rural, a perspectiva do realismo e, dentro dos limites permitidos durante o período ditatorial, as temáticas sociais fizeram-se presentes.

Entendemos que o Brasil enfrentou, a partir da década de 1970, um processo de despolitização das artes determinado tanto pelo recrudescimento da ditadura militar quanto pelo desenvolvimento de uma indústria cultural que tenderá a circunscrever a liberdade criativa do artista "a limites bem determinados" (ORTIZ, 1994, p. 147). Esse quadro, é claro, impactou fortemente a produção das telenovelas, cujos autores não contaram com a relativa liberdade desfrutada pelos realizadores radiofônicos do início dos anos 1950. Ainda assim, acreditamos que algumas das características citadas, as quais se tornariam elementos distintivos das telenovelas brasileiras, surgiram também em consequência do processo de politização da estética radiofônica no período imediatamente anterior, inclusive pela presença de Dias Gomes nessas duas áreas de produção.

Nesse sentido, gostaríamos de pensar as imbricações entre a radionovela e a telenovela a partir de um processo oposto, ainda que complementar: a influência da telenovela na renovação da linguagem da radionovela ocorrida durante o revival do gênero nos anos 1980.

\section{Projeto Radiofônico da SSC\&B-Lintas}

As empresas Cia. Gessy Industrial (brasileira) e Lever Brothers (anglo-holandesa), conhecidas, respectivamente, por seus sabonetes Gessy e Lever (depois Lux), foram concorrentes durante a Era de Ouro do rádio brasileiro (décadas de 1940 e 1950). Em 1960, no entanto, ocorre a aquisição das Indústrias Gessy pela Lever Brothers, com a nova empresa assumindo a denominação de Indústrias Gessy Lever. A Lintas, Lever International Advertising Services, a house agency da Lever, cuidava da publicidade dos diferentes produtos da empresa e foi instalada no país em 1931. A denominação SSC\&B-Lintas foi resultante de sua fusão com a agência de publicidade norte-americana Sullivan, Stauffer, Colwell and Bayles, ocorrida em $1967^{9}$.

Como a televisão já se encontrava em grande processo de expansão no país durante os anos 1960, a Gessy Lever acabou por concentrar seus investimentos publicitários nesse veículo. Em 1964, por exemplo, a empresa patrocinou a versão televisiva de $O$ Direito de Nascer, lançada com enorme sucesso em dezembro daquele ano (UNILEVER, 2001, p. 29).

Apesar de seu foco na televisão, a Gessy Lever manteve uma prática de produzir radionovelas, 
gravá-las e distribuir os tapes a emissoras de rádio do interior do país. Essa prática fora iniciada pela Lever Brothers nos anos 1950, com a chegada dos gravadores de fita ao Brasil. Assim, em lugar de pagar pela veiculação de seus comerciais no rádio, a empresa os incluía nas radionovelas que produzia e distribuía gratuitamente às emissoras. Segundo Valvênio Martins, que começou a trabalhar na área de rádio da Lintas em 1986, as radionovelas eram, normalmente, versões de roteiros escritos nos anos 1950 e, quando possível, eram utilizados os mesmos atores que haviam atuado nas gravações originais. Assim, os novos trabalhos "eram interpretados daquela maneira clássica da radionovela"10, caracterizando uma dinâmica constante de trocas entre gêneros radiofônicos e televisivos.

Geraldo Leite, que foi supervisor de planejamento de mídia da SSC\&B-Lintas, explica que, embora o rádio já não fosse a principal estratégia publicitária da empresa para os grandes centros urbanos, ele ainda se mantinha como um meio eficiente para atingir o público de cidades do interior, especialmente das regiões Norte, Nordeste e Centro-Oeste ${ }^{11}$.

Dezenas de horas de gravações de radionovelas e peças radiofônicas produzidas pela SSC\&B-Lintas foram disponibilizadas aos autores deste trabalho por Fabiana Nogueira e Viviani Alves, do Centro de História da Unilever Brasil ${ }^{12}$. Nesse acervo, consta uma produção da década de 1970 que contraria a afirmação de Valvênio Martins sobre as regravações de roteiros antigos: trata-se da adaptação radiofônica de Irmãos Coragem, telenovela de Janete Clair. Irmãos Coragem foi exibida pela Rede Globo entre 08/06/1970 e 12/06/1971 ${ }^{13}$. A obra é apresentada como "uma adaptação radiofônica de Urbano Lóes da mais famosa novela de Janete Clair". Não temos como precisar quando exatamente essa radionovela foi veiculada, mas, certamente, foi no início dos anos 1970.

\section{Irmãos Coragem conta a história de três} irmãos que lutam, em uma fictícia cidade do interior do país, contra as arbitrariedades de um grande proprietário de terras local. Sua linguagem visual e temática estão muito próximas dos filmes de western, e a influência dos filmes de Sérgio Leone é bastante evidente na obra (especialmente na trilha musical).

Já a radionovela parece ficar mais próxima do padrão sonoro da telenovela do que da tradição das radionovelas. Em primeiro lugar, nas interpretações. Não temos a fala mais lenta e a

10 Valvênio Martins em depoimento concedido aos autores e a Carlos Eduardo Minehira,em 16/10/2009.

Geraldo Leite em depoimento concedido aos autores, em 06/09/2014.

12 A denominação Unilever seria adotada pela empresa em 2001 (Unilever, 2001, p.145).

13 Ver: http://memoria globo.globo.com/programas/entretenimento/novelas/irmaos-coragem-1-versao/trilha-sonora.htm. Acesso em: 16/01/2015. 
interpretação carregada, que caracterizaram as radionovelas dos anos 1940 e 1950. As vozes ficam mais próximas do tom coloquial, do naturalismo dos atores televisivos. Por se tratar de uma novela que se passa no meio rural, temos ainda o uso de sotaques, expressões locais e mesmo de incorreções gramaticais. Exatamente como acontecia na telenovela. Outro detalhe fundamental na produção é a completa ausência do narrador onisciente.

Assim, em Irmãos Coragem o ouvinte acompanha a narrativa exclusivamente a partir dos diálogos, da música e dos efeitos sonoros.

Mas será a partir de 1981, sob a direção do publicitário Castro Negrão, que a SSC\&BLintas iniciará um amplo projeto de renovação e ampliação de sua produção de radionovelas e peças radiofônicas, utilizando roteiros originais e contratando uma grande equipe de atores, técnicos e músicos. 0 projeto irá se tornar o mais importante do gênero desenvolvido no país desde a década de 1960, e a televisão, também nesse caso, será 0 grande referencial para a atualização da linguagem radiofônica então proposta, pois

(...) a fórmula do folhetim lacrimejante, onde os personagens sempre eram emboscados pelo destino, e que tanto deu certo nos anos 50, não vinha provocando nem comoção e muito menos vontade de 0 ouvinte ligar 0 rádio. A televisão foi a principal responsável por essa mudança de comportamento. Ela mudou o gênero, embora a estrutura do folhetim ainda permaneça invencível (Revista Afinal, 05/03/1985, p. 5) ${ }^{14}$.
Nessa e em outras reportagens, a equipe da SSC\&B-Lintas deu diversas indicações do que pretendia com as novas produções: “(...) um casamento entre os elementos mais clássicos da radionovela - aqueles herdados do folhetim como o suspense de um capítulo para o outro, a inspiração lírica, etc. - e a linguagem e a interpretação coloquial de nossos dias" (Revista Metro News, 25/07/1983). Produções onde os personagens "sofrem os mesmos dramas e dificuldades do público" (Revista Meio e Mensagem, julho de 1983). Para isso, "em vez dos antigos radioatores e dubladores, foram chamados atores que nunca haviam feito rádio" (Revista Afinal, 05/03/1985, p. 5).

Em relação às temáticas das produções, uma análise das radionovelas e peças radiofônicas disponibilizadas mostra um quadro um pouco diferente daquele das telenovelas. Em primeiro lugar, o interior do país está mais presente do que as grandes cidades, o que é compreensível se considerarmos que era para o público do interior que as produções foram direcionadas. Em segundo, as radionovelas evitavam temas polêmicos, sendo muitas das produções adaptações de textos clássicos da literatura brasileira, histórias de terror, histórias de superação ou trabalhos voltados ao público infantil.

Entendemos que as produções mais densas do projeto da SSC\&B-Lintas são devidas a Carlos 
Alberto Soffredini (1939-2001), certamente, o mais importante de seus roteiristas. Autor e diretor de teatro, além de fundador do Grupo de Teatro Mambembe, Soffredini desenvolveu um amplo trabalho de pesquisa sobre 0 teatro popular, e foi essa experiência que ele levou para a sua atuação no âmbito das radionovelas. Suas principais produções para a SSC\&B-Lintas foram Anita, Heroína por Amor (1983), com 78 capítulos, e Sal da Terra (1987), com 30 capítulos.

Ambientadas no passado, ambas resgatavam a trajetória de personagens da história do país oriundos das classes trabalhadoras, como Anita Garibaldi (1821-1849), heroína da Revolução Farroupilha (1835-1845), e Antônio Conselheiro (1830-1897), o personagem central da Guerra de Canudos, que opôs seus seguidores ao governo brasileiro entre os anos de 1896 e 1897. Nas duas radionovelas, há uma grande preocupação com a exatidão histórica da narrativa, bem como com o uso das músicas, da linguagem e do sotaque de cada região (a região Sul, no caso de Anita, e a Nordeste, no caso de Sal da Terra).

Em Sal da Terra, são utilizados também os cânticos religiosos entoados pelos seguidores de Conselheiro. Para escrever esta radionovela, Soffredini permaneceu por um período na região do conflito pesquisando arquivos e entrevistando moradores (Revista Afinal, 05/03/1985, p. 5).

A questão da trilha musical das produções recebeu um cuidado especial por parte dos seus responsáveis. Paulo Tatit e Helio Ziskind foram os autores de muitas das trilhas instrumentais e também de canções originais utilizadas como temas de abertura de várias séries radiofônicas e radionovelas do projeto. 0 uso que ambos fazem nas trilhas de sintetizadores, guitarras e outros recursos eletrônicos representa um importante trabalho de renovação da trilha musical do rádio ficcional no Brasil, até aquele momento vinculada quase que exclusivamente à música orquestral.

Outro ponto que pode ser destacado quanto à estética das produções é a forma pela qual os realizadores buscaram se afastar das radionovelas tradicionais também por meio da recusa ao uso convencional do narrador onisciente. Produções de autores que, posteriormente, se agregaram ao projeto, como Zeca Ibanez, Raul Reis e Enéas Carlos Pereira, não se utilizaram de tal recurso. Esse é o caso, entre muitos outros, da radionovela Férias, Caminhões e Confusões (Enéas Carlos Pereira, 1986), da peça radiofônica De Volta ao Lar (Zeca Ibanez, 1990) e da série radiofônica Histórias do Sertão (Raul Reis, 1986).

Em Sal da Terra (Carlos Alberto Soffredini, 1987), produção que exige a apresentação ao ouvinte de uma grande quantidade de informações históricas e que tem uma clara preocupação didática, 0 narrador não pôde ser evitado. Porém, ele assumiu uma forma bem menos tradicional: a de um personagem com forte sotaque nordestino que se dirige diretamente ao ouvinte contando fatos ou versões da saga de Conselheiro que havia lido ou ouvido de diferentes fontes. Não se trata, portanto, 
de um narrador "onisciente", mas de uma pessoa comum, que expõe suas dúvidas e chega até a relatar as diferentes versões que ouviu sobre um mesmo acontecimento sem tomar posição em relação a elas.

Tanto pelas razões apontadas anteriormente, como pelo uso que fez de recursos tecnológicos como a edição em multicanais, a gravação de sons ambientes e 0 uso de música sintetizada ${ }^{15}$, entendemos o projeto da SSC\&B-Lintas como um importante momento de atualização da linguagem do rádio ficcional no Brasil. Além disso, parece-nos clara a conexão entre o projeto e a efervescente cena cultural paulistana do período. Além de Soffredini e de muitos autores e atores teatrais de grupos independentes como Mambembe, Tapa e Irmãos Bambulha terem atuado no projeto, Geraldo Leite, Paulo Tatit e Helio Ziskind eram integrantes do Grupo Rumo, o que aproximava o projeto também da chamada Vanguarda Paulistana e, portanto, da cena musical independente da cidade.

\section{0 projeto radiofônico da SSC\&B-Lintas seria} encerrado em 1991. Juntamente com a grave crise econômica enfrentada pelo país no período, 0 "avanço da televisão no mercado brasileiro" foi apontado como a principal razão para 0 fim do projet $^{16}$. Com ele, encerrava-se um dos grandes momentos da radionovela no Brasil, que, nos anos seguintes, praticamente desapareceria da programação de suas emissoras comerciais.

\section{Considerações finais}

A intenção deste artigo foi apresentar alguns aspectos da produção brasileira de radionovelas evidenciando as relações que 0 gênero estabelece com a produção de telenovelas. Nas telenovelas não prevaleceram as interpretações carregadas, o protagonismo das classes abastadas e a preferência por locais exóticos que caracterizaram as radionovelas tradicionais. Contudo, tentamos demonstrar que tendências que se tornariam dominantes nas telenovelas como o realismo, a interpretação naturalista, o protagonismo das classes trabalhadoras e 0 foco na contemporaneidade também já estavam presentes no rádio brasileiro, ao menos, nos trabalhos de maior engajamento político de autores como Dias Gomes, Túlio de Lemos e Osvaldo Molles.

0 ressurgimento da radionovela no país ao longo da década de 1980, a partir do projeto desenvolvido pela SSC\&B-Lintas, demonstra que a atualização dessa produção passou pela incorporação de muitas das características da telenovela, como as interpretações despojadas, a redução da presença do narrador onisciente, 0 desenvolvimento de tramas focadas em temáticas 
nacionais ou regionais, e a valorização de uma trilha musical mais diversificada (inclusive com 0 uso da canção popular).

Entendemos que, dentro dos limites do artigo, não seria possível oferecer uma visão mais detalhada sobre a história e as características do rádio ficcional no Brasil. Porém, esperamos que 0 texto possa ajudar a demonstrar a importância da realização de mais estudos sobre 0 tema, bem como da organização de acervos de roteiros, gravações e da recuperação da memória de autores.

Acreditamos firmemente que o rádio, em sua era digital, demanda esse esforço de reavaliação e de atualização da discussão sobre a sua história, autores e gêneros no sentido de enfatizar as múltiplas potencialidades de uso social e culturalmente relevante dessa "velha nova mídia". E, sobretudo, debates que articulem questões contemporâneas voltadas aos hibridismos e convergências midiáticas, não apenas em termos de gêneros e formatos, mas também de processos e linguagens audiovisuais.

\section{Referências}

BORELLI, S. H. S.; MIRA, M. C. Sons, imagens, sensações: radionovelas e telenovelas no Brasil. In: Intercom - Revista Brasileira de Comunicação. São Paulo: Intercom, vol. XIX, n.1, 1996, pp. 33-57.

CALABRE, L. 0 rádio na sintonia do tempo: radionovelas e cotidiano (1940-1946). Rio de Janeiro: Edições Casa de Rui Barbosa, 2006.
. No tempo das radionovelas.

Comunicação \& Sociedade, n. 49, 2007, pp. 65-83.

DIAS GOMES, A. Apenas um subversivo.

Rio de Janeiro: Bertrand Russell, 1998.

GOLDEFEDER, M. Por trás das ondas da Rádio

Nacional. Rio de Janeiro: Paz e Terra, 1990.

GURERRINI, JR., I. Tulio de Lemos e seus admiráveis roteiros. São Paulo: Terceira Margem, 2013.

MATTELART, M; MATTELART, A. The carnival of images: Brazilian television fiction. New York: Bergin \& Garvey Publishers, 1990.

MUGNAINI Jr, Ayrton. Dá Licença de Eu Contar. São Paulo: Editora 34, 2002.

MURAKAMI, M. Da fantasia ao transmídia: modernização do gênero telenovela. Tese de Doutorado. São Paulo: ECA/USP, 2015.

NAPOLITANO, M. 0 PCB e a resistência cultural comunista (1964-1968). In: ROX0, M.; SACRAMENTO, I. (org.). Intelectuais partidos: os comunistas e as mídias no Brasil. Rio de Janeiro: E-Papers, 2013.

ORTIZ, R. A evolução histórica da telenovela. In: ORTIZ, R.; BORELLI, S. H. S.; RAMOS, J. M. 0. (org.). Telenovela: história e produção. São Paulo: Brasiliense, 1991. . A moderna tradição brasileira.

São Paulo: Brasiliense, 1994.

UNILEVER. Gessy Lever: história e histórias de intimidade com o consumidor brasileiro. São Paulo: Unilever, 2001.

VIANNA, D. Companheiros de viagem. São Paulo: Brasiliense, 1984.

VICENTE, E. Radiodrama em São Paulo: A História de Zé Caolho, de Dias Gomes. In: Revista Observatório, v.7, 2013, pp. 173-185. 


\section{Depoimentos}

Geraldo Leite, depoimento concedido aos autores em 06/09/2014.

José Castellar, depoimento concedido ao IDART/ CCSP, 1979.

José Castellar, depoimento concedido a Eliana Lobo de Andrade Jorge, Idart/CCSP, 21/07/1978.

Valvênio Martins, depoimento concedido aos autores e a Carlos Eduardo Minehira em 16/10/2009. 


\begin{tabular}{|c|c|}
\hline $\begin{array}{l}\text { Between radio and television: } \\
\text { genesis and transformation } \\
\text { of Brazilian soap operas }\end{array}$ & $\begin{array}{l}\text { Entre la radio y la televisión: } \\
\text { génesis y transformación } \\
\text { de las "novelas" brasileñas }\end{array}$ \\
\hline $\begin{array}{l}\text { Abstract } \\
\text { The present work provides a perspective on } \\
\text { radionovela in Brazil and the relationship such genre } \\
\text { has historically kept with that of telenovela. Two main } \\
\text { trends can be identified in Brazilian radio tradition: } \\
\text { one more commercial, melodramatic and conservative } \\
\text { and other more realistic and politically engaged. } \\
\text { Despite being less present in the radio programming, } \\
\text { the second trend had an undeniable impact in the } \\
\text { development of the telenovela in the country. Later } \\
\text { on, Telenovela itself became the main reference for the } \\
\text { renovation of the language of radio drama as produced } \\
\text { within the } 80 \text { 's SSC\&B Lintas project. } \\
\text { Keywords } \\
\text { Media history. Radio fiction. Radioplay. Soap 0pera. }\end{array}$ & $\begin{array}{l}\text { Resumen } \\
\text { Este artículo observa la tradición de la radionovela } \\
\text { en Brasil y las relaciones históricamente establecidas } \\
\text { entre ésta y la telenovela. En primer lugar, presentamos } \\
\text { dos tendencias principales en nuestro radioteatro: } \\
\text { una más comercial, conservadora y correspondiente } \\
\text { al melodrama; otra más realista y políticamente } \\
\text { comprometida. Debatiremos a lo largo de nuestro } \\
\text { trabajo sobre como la segunda tendencia, aunque } \\
\text { menos presente en la radio, ha tenido gran importancia } \\
\text { en el desarrollo de la telenovela nacional. Por fin, } \\
\text { argüimos que la telenovela fue la principal referencia } \\
\text { para la renovación del lenguaje como utilizado pelo } \\
\text { proyecto de SSC\&B Lintas durante los años } 80 . \\
\text { Palabras clave } \\
\text { Historia de los medios. Ficción de la radio. Radionovela. } \\
\text { Telenovela. }\end{array}$ \\
\hline
\end{tabular}




\section{Expediente}

A revista E-Compós é a publicação científica em formato eletrônico da Associação Nacional dos Programas de Pós-Graduação em Comunicação (Compós). Lançada em 2004, tem como principal finalidade difundir a produção acadêmica de pesquisadores da área de Comunicação, inseridos em instituições do Brasil e do exterior.

\section{E-COMPÓS I www.e-compos.org.br I E-ISSN 1808-2599}

Revista da Associação Nacional dos Programas de Pós-Graduação em Comunicação. Brasília, v.19, n.2, maio/ago. 2016. A identificação das edições, a partir de 2008, passa a ser volume anual com três números. Indexada por Latindex I www.latindex.unam.mx

\section{CONSELHO EDITORIAL}

\section{Alexandre Farbiarz, Universidade Federal Fluminense, Brasi}

Alexandre Rocha da Silva, Universidade Federal do Rio Grande do Sul, Brasil Ana Carolina Escosteguy, Pontifícia Universidade Católica do Rio Grande do Sul, Brasil Ana Carolina Rocha Pessôa Temer, Universidade Federal de Goiás, Brasil Ana Regina Barros Rego Leal, Universidade Federal do Piauí, Brasil Andrea França, Pontifícia Universidade Católica do Rio de Janeiro, Brasil André Luiz Martins Lemos, Universidade Federal da Bahia, Brasil Antonio Carlos Hohlfeldt, Pontifícia Universidade Católica do Rio Grande do Sul, Brasil Arthur Ituassu, Pontifícia Universidade Católica do Rio de Janeiro, Brasil Álvaro Larangeira, Universidade Tuiuti do Paraná, Brasil

Ângela Freire Prysthon, Universidade Federal de Pernambuco, Brasil César Geraldo Guimarães, Universidade Federal de Minas Gerais, Brasil Cláudio Novaes Pinto Coelho, Faculdade Cásper Líbero, Brasil Daisi Irmgard Vogel, Universidade Federal de Santa Catarina, Brasil Denize Correa Araujo, Universidade Tuiuti do Paraná, Brasil Eduardo Antonio de Jesus, Pontifícia Universidade Católica de Minas Gerais, Brasil Daniela Zanetti, Universidade Federal do Espírito Santo, Brasil Eduardo Vicente, Universidade de São Paulo, Brasil

Elizabeth Moraes Gonçalves, Universidade Metodista de São Paulo, Brasil Erick Felinto de Oliveira, Universidade do Estado do Rio de Janeiro, Brasil Francisco Elinaldo Teixeira, Universidade Estadual de Campinas, Brasil Francisco Paulo Jamil Almeida Marques, Universidade Federal do Paraná, Brasil Gabriela Reinaldo, Universidade Federal do Ceará, Brasil

Goiamérico Felício Carneiro Santos, Universidade Federal de Goiás, Brasil Gustavo Daudt Fischer, Universidade do Vale do Rio dos Sinos, Brasil Herom Vargas, Universidade Municipal de São Caetano do Sul, Brasil Itania Maria Mota Gomes, Universidade Federal da Bahia, Brasil Janice Caiafa, Universidade Federal do Rio de Janeiro, Brasil Jiani Adriana Bonin, Universidade do Vale do Rio dos Sinos, Brasil
José Afonso da Silva Junior, Universidade Federal de Pernambuco, Brasil José Luiz Aidar Prado, Pontifícia Universidade Católica de São Paulo, Brasil Juçara Gorski Brittes, Universidade Federal de Ouro Preto, Brasil Kati Caetano, Universidade Tuiuti do Paraná, Brasil Lilian Cristina Monteiro França, Universidade Federal de Sergipe, Brasil Liziane Soares Guazina, Universidade de Brasilia, Brasil Luíza Mônica Assis da Silva, Universidade de Caxias do Sul, Brasil Luciana Miranda Costa, Universidade Federal do Pará, Brasil Malena Segura Contrera, Universidade Paulista, Brasil Monica Martinez, Universidade de Sorocaba, Brasil Maria Ataide Malcher, Universidade Federal do Pará, Brasil Marcia Tondato, Escola Superior de Propaganda e Marketing, Brasil Marcel Vieira Barreto Silva, Universidade Federal da Paraiba, Brasil Maria Clotilde Perez Rodrigues, Universidade de São Paulo, Brasil Maria das Graças Pinto Coelho, Universidade Federal do Rio Grande do Norte, Brasil Mauricio Ribeiro da Silva, Universidade Paulista, Brasil

Mauro de Souza Ventura, Universidade Estadual Paulista, Brasil Márcio Souza Gonçalves, Universidade do Estado do Rio de Janeiro, Brasil Micael Maiolino Herschmann, Universidade Federal do Rio de Janeiro, Brasil Mirna Feitoza Pereira, Universidade Federal do Amazonas, Brasil Nísia Martins Rosario, Universidade Federal do Rio Grande do Sul, Brasil Potiguara Mendes Silveira Jr, Universidade Federal de Juiz de Fora, Brasil Regiane Regina Ribeiro, Universidade Federal do Paraná, Brasil Rogério Ferraraz, Universidade Anhembi Morumbi, Brasil Rose Melo Rocha, Escola Superior de Propaganda e Marketing, Brasil Rozinaldo Antonio Miani, Universidade Estadual de Londrina, Brasil Sérgio Luiz Gadini, Universidade Estadual de Ponta Grossa, Brasil Simone Maria Andrade Pereira de Sá, Universidade Federal Fluminense, Brasil Veneza Mayora Ronsini, Universidade Federal de Santa Maria, Brasil Walmir Albuquerque Barbosa, Universidade Federal do Amazonas, Brasil
COMISSÃO EDITORIAL Eduardo Antonio de Jesus, Pontifícia Universidade Católica de Minas Gerais, Brasil I Osmar Gonçalves dos Reis Filho, Universidade Federal do Ceará, Brasi

CONSULTORES AD HOC Alexandre Almeida Barbalho, Universidade Estadual do Ceará, Brasil | Alexandre Rocha da Silva, Universidade Federal do Rio Grande do Sul, Brasil | Bruno Souza Leal, Universidade Federal de Minas Gerais, Brasil I Carlos Eduardo Franciscato, Universidade Federal do Sergipe, Brasil I Eneus T. Barreto Filho, Universidade de São Paulo, Brasil I Felipe da Costa Trotta, Universidade Federal Fluminense, Brasi | Henrique Codato, Universidade Federal do Ceará, Brasil I Ines S. Vitorino Sampaio Universidade Federal do Ceará, Brasil I Jairo Getulio Ferreira, Universidade do Vale do Rio dos Sinos, Brasil I Juliana Freire Gutmann, Universidade Federal da Bahia, Brasil | Júlio César M. Pinto, Pontifícia Universidade Católica de Minas Gerais, Brasil I Lucrecia D. Ferrara, Pontifícia Universidade Católica de São Paulo, Brasil I Marcio V. Serelle, Pontifícia Universidade Católica de Minas Gerais, Brasil I Maria Ignes C. Magno, Universidade Anhemb Morumbi, Brasil I Maria Lilia Dias de Castro, Universidade Federal de Santa Maria, Brasil Mozahir S. Bruck, Pontifícia Universidade Católica de Minas Gerais, Brasil I Potiguara M. da Silveira Junior, Universidade Federal de Juiz de Fora, Brasil I Sandra Maria L. P. Gonçalves, Universidade Federal do Rio Grande do Sul, Brasil I Suzana Kilpp, Universidade do Vale do Rio dos Sinos, Brasil I Tiago Q. Fausto Neto, Universidade de Brasília, Brasil I Vera Regina V. Franca, Universidade Federal de Minas Gerais, Brasil I Virginia P. S. Fonseca, Universidade Federal do Rio Grande do Sul, Brasil

EQUIPE TÉCNICA ASSISTENTE EDITORIAL Márcio Zanetti Negrini REVISÃo DE TEXTOS Press Revisão I EDITORAÇÃO ELETRÔNICA Roka Estúdio

\section{COMPÓS I www.compos.org.br}

Associação Nacional dos Programas de Pós-Graduação em Comunicação

Presidente

Edson Fernando Dalmonte

Programa de Pós-Graduação em Comunicação

e Cultura Contemporânea - UFBA

edsondalmonte@uol.com.br

Vice-presidente

Cristiane Freitas Gutfreind

Programa de Pós-Graduação em Comunicação Social - PUC-RS cristianefreitas@pucrs.br

Secretário-Geral

Rogério Ferraraz

Programa de Pós-Graduação em Comunicação

Universidade Anhembi Morumbi

rogerioferraraz@anhembimorumbi.edu.br

CONTATO I revistaecompos@gmail.com 